\title{
The economic impact of moderate stage Alzheimer's disease in Italy: evidence from the UP-TECH randomized trial
}

\author{
Carlos Chiatti, ${ }^{1}$ Gianluca Furneri, ${ }^{1}$ Joseph M. Rimland, ${ }^{1}$ Federica Demma, ${ }^{1}$ \\ Franco Bonfranceschi, ${ }^{1}$ Laura Cassetta, ${ }^{1}$ Filippo Masera, ${ }^{2}$ Antonio Cherubini, ${ }^{1}$ \\ Andrea Corsonello ${ }^{1}$ and Fabrizia Lattanzio, ${ }^{1}$ on behalf of the UP-TECH research group ${ }^{3}$ \\ ${ }^{1}$ Italian National Research Center on Aging (INRCA), Ancona, Italy \\ ${ }^{2}$ Marche Regional Health Agency, Ancona, Italy
}

ABSTRACT

Background: There is consensus that dementia is the most burdensome disease for modern societies. Few cost-of-illness studies examined the complexity of Alzheimer's disease (AD) burden, considering at the same time health and social care, cash allowances, informal care, and out-of-pocket expenditure by families.

Methods: This is a comprehensive cost-of-illness study based on the baseline data from a randomized controlled trial (UP-TECH) enrolling 438 patients with moderate $\mathrm{AD}$ and their primary caregiver living in the community.

Results: The societal burden of $\mathrm{AD}$, composed of public, patient, and informal care costs, was about $€ 20,000 / y r$. Out of this, the cost borne by the public sector was $€ 4,534 / y$. The main driver of public cost was the national cash-for-care allowance $(€ 2,324 / \mathrm{yr})$, followed by drug prescriptions $(€ 1,402 / \mathrm{yr})$. Out-of-pocket expenditure predominantly concerned the cost of private care workers. The value of informal care peaked at $€ 13,590 / y r$. Socioeconomic factors do not influence AD public cost, but do affect the level of out-of-pocket expenditure.

Conclusion: The burden of $\mathrm{AD}$ reflects the structure of Italian welfare. The families predominantly manage $\mathrm{AD}$ patients. The public expenditure is mostly for drugs and cash-for-care benefits. From a State perspective in the short term, the advantage of these care arrangements is clear, compared to the cost of residential care. However, if caregivers are not adequately supported, savings may be soon offset by higher risk of caregiver morbidity and mortality produced by high burden and stress. The study has been registered on the website www.clinicaltrials.org (Trial Registration number: NCT01700556).

Key words: cost analysis, Alzheimer's disease, UP-TECH, RCT, caregiver, community-living

Correspondence should be addressed to: Joseph M. Rimland, Italian National Research Center on Aging (INRCA), Ancona, Italy. Phone: +39-0718004787; Fax: +39-071-35941. Email: j.rimland@inrca.it. Received 3 Jun 2014; revision requested 23 Jul 2014; revised version received 25 Nov 2014; accepted 3 Mar 2015. First published online 15 April 2015.

${ }^{3}$ This paper was prepared on behalf of the UP-TECH multidisciplinary research group. Social workers: Diletta Baldassarri, Luigina Bitti, Aurora Carosi, Maila Sabbatini, Elisabetta Paolasini, Tania Fiori, Cinzia Fronzi, Simona Giacchetta, Valeria Giacomini, Laura Giovagnoli, Giuli Lattanzi, Anna Maria Manca, Ida Marinelli, Valeria Pigini, Marina Pignotti, Maria Chiara Proietti, Antonia Quarticelli, Martina Rovedi, Letizia Tasso, and Valentina Valeri. Nurses: Andrea Antonioli, Mariella Barabucci, Mara Bassani, Paola Bollettini, M Cristina Bruttapasta, Carla Buccolini, Rosa Carangella, Franca Carboni, Daniela Ceccolini, Patrizia D'Incecco, Mariangela Di Felice, Lara Dini, Giordano Gioia, Giuseppe Di Prima, Giancarlo Giusepponi, Cesarina Lanciotti, Alessia Loffreda, Oriana Luciani, Laura Mariani, Francesco Mastrorilli, Roberto Moroni, Izabela Piatkowska, Roberta Rucoli, Giampaola Scoccia, Nives Teodori, and Tiziana Tonelli. Physicians: Rossano Angeloni, Rosa Anna Bratti, Giuseppe Bonafede, Severino Lorenzetti, Cristina Paci, Giovanna Picciotti, Donella Pezzola, Vincenzo Rea, Vittorio Scialè, Mario Signorino, Francesca Sorvillo, and Pia

\section{Introduction}

Dementia is becoming one of the main causes of disability in developed countries (WHO and ADI, 2012). In 2010, it has been estimated that worldwide, about 35.6 million people 65 years and older had dementia. This number is expected

\footnotetext{
Francesca Tomassini. Psychologists: Alessia Ciccola and Loena Cionfrini. Social services managers: Daniela Alessandrini, Antonio De Santis, Brunetta Formica, Giuliano Tacchi, Silvia Tortorelli. Marche Regional Authority: Gemma Marchegiani, Giovanni Pozzari, and Giovanni Santarelli. General Practitioners: Dario Bartolucci. UP-TECH scientific committee: Giorgio Caraffa, Filippo Cavallo, Lucia Di Furia, Antonio Lacetera, Claudio M Maffei, Lamberto Manzoli and Demetrio Postacchini. INRCA working group: Roberta Bevilacqua, Anna Rita Bonfigli, Silvia Bustacchini, Marina Capasso, Patrizia Civerchia, Federica Demma, Mirko Di Rosa, Cinzia Giuli, Marzio Marcellini, Paolo Marinelli, Gabriella Melchiorre, Maria Elena Moraca, Andrea Principi, Cristina Rocchetti, Liana Spazzafumo and Daniela Vincitorio. Virtual counter for technologies: Krystian Bartulewicz, Paolo Olivetti and Lorena Rossi.
} 
to nearly triple in the next 40 years (Thies and Bleiler, 2011), as the prevalence and incidence of dementia increase exponentially with age in older subjects (Jorm and Jolley, 1998; Ferri et al., 2005). There is wide consensus that dementia is one of the most burdensome diseases for welfare systems, but establishing the costs incurred by this illness is a complex process (Costa et al., 2012).

Previous cost-of-illness studies have used a wide array of methods in an attempt to encompass cost elements, but this has led to heterogeneous findings (Schneider et al., 1999; Prince, 2004; Jonsson and Wimo, 2009; Hurd et al., 2013; Leicht et al., 2013). In Europe, healthcare cost estimates of Alzheimer's disease (AD) patients ranged from $€ 6,435$ (in France) to $€ 64,426$ per patient per year (in the United Kingdom), with a clear trend of increased costs with AD severity (Jonsson and Wimo, 2009). Informal care may account for up to $81 \%$ of the total cost for care (Boada et al., 1999). The unpaid time of caregivers ranged from $\$ 5,655$ (mild AD) to $\$ 3,506$ (severe $\mathrm{AD}$ ) for supervising their family members and from $\$ 9,451$ (mild $\mathrm{AD}$ ) to $\$ 36,794$ (severe $\mathrm{AD}$ ) for direct care provision (Hux et al., 1998).

It is known that $\mathrm{AD}$ cost is highly dependent on the setting of care (community vs. residential vs. hospital). Moreover, it has been estimated that delaying a patient's institutionalization can save US $\$ 1,863$ per month (Leon et al., 1998). These findings reinforce the importance of studies to inform cost-effective strategies aimed at avoiding institutionalization of $\mathrm{AD}$ patients.

Two previous cost-of-illness studies have been carried out in Italy (Cavallo and Fattore, 1997; Trabucchi, 1999), however, neither study comprehensively evaluated all cost categories (e.g., costs of medical care, cash-for-care allowances, and families' out-of-pocket expenditure), nor included data on AD severity. Furthermore, these studies did not investigate patient and caregiver correlates of cost.

The UP-TECH study is a multicenter, randomized controlled clinical trial in Italy, that enrolled 438 AD patient-caregiver dyads into three arms. This clinical trial is investigating whether innovative interventions, such as case management and new technologies can improve the costeffectiveness of care processes for older people with AD (Chiatti et al., 2015). The baseline assessment performed on the enrolled patients included an indepth evaluation of the use of care resources, which allowed a detailed cost-of-illness study. The results can address important gaps in the economic analysis of $\mathrm{AD}$ in Italy and represents a valuable opportunity to inform policy.

\section{Methods}

The UP-TECH study was extensively described elsewhere (Chiatti et al., 2013b). Briefly, lists of AD patients were obtained from the Alzheimer's Evaluation Units (AEUs) from five health districts of the Marche Region (Pesaro, Ancona, Macerata, Fermo, San Benedetto del Tronto). Eligible subjects were patients with a diagnosis of $\mathrm{AD}$ according to the NIA-AA 2011 criteria (Albert et al., 2011; McKhann et al., 2011), with a MiniMental State Examination (MMSE) (Folstein et al., 1975) score between 10 and 20, corresponding to moderate stage $\mathrm{AD}$, and assisted at home by at least one family caregiver (although not necessarily living with the caregiver herself/himself). We included only patients with moderate $\mathrm{AD}$ as we hypothesized that the impact of the interventions tested could be more evident and cost-effective in this subpopulation (e.g. caregiver burden was not too high at enrollment). An invitation letter was sent to 653 patient-family caregiver dyads retrieved from the AEU lists who met the eligibility criteria, asking them to participate in the research study: at the end of the recruitment, 438 dyads were enrolled in the project, resulting in a response rate of approximately $67 \%$ (more methodological details are described in the protocol and the recruitment papers (Chiatti et al., 2013b; 2015)). Data have been collected between January 2013 and July 2013. All 438 dyads completed baseline assessment and were included in the present analysis.

The UP-TECH database was integrated through record linkage with the data on hospitalizations from the Regional administrative register of hospital discharges. The study was submitted to the Regional Ethics Committee, which consented to the study being carried out.

\section{Study variables}

After obtaining a written informed consent, a trained nurse administered a structured questionnaire, which was a modified version of the InterRAI Contact Assessment (interRAI CA, Ann Arbor, MI, USA) (Hirdes et al., 2010). Instrumental activities of daily living (IADL)-performance (BarbergerGateau et al., 1992) and activities of daily living (ADL)-hierarchy scales (Morris et al., 1999) were assessed to estimate the level of cognitive and physical performance of the patients. The IADL Involvement Scale, which is based on a sum of seven IADL-related items, produces a scale that ranges from 0 to 48 , with higher scores indicating greater difficulty. ADL dependency was summarized using the ADL Hierarchy Scale which ranges from 0 (no impairment) to 6 (total dependence). The caregiver's burden was evaluated 
by administering the Caregiver Burden Inventory (CBI) scale, developed by Novak and Guest (1989) and validated in Italy (Marvardi et al., 2005). The CBI is a multidimensional questionnaire composed of five subscales: time-dependence burden, developmental burden, physical burden, social burden, and emotional burden. Overall, it includes a set of 24 items evaluated using a fivepoint Likert scale ranging from 0 (not at all) to 4 (very much), which are summed. (Scores can vary from 0 to 96 , with higher scores indicating greater caregiver distress). Behavioral disturbances of patients were appraised by asking caregivers if the patient displayed, in the last three days, one or more of the following symptoms: verbal or physical aggression, socially inappropriate behavior, socially inappropriate sexual behavior, and/or wandering.

We used caregivers' educational attainment and occupation as proxies of dyad socioeconomic status (SES) (Huisman et al., 2003). Educational level was categorized according to the years of formal education completed: no title-primary school (up to 5 years); intermediate (6-8 years); high (9-14 years); university degree or higher $(>15$ years). Caregivers were grouped into social classes using present occupation, or their last job before retirement (De Lillo and Schizzerotto, 1985; Cardano et al., 2004).

\section{Cost items}

Data regarding the use of resources in the six months prior to the first interview (July 2012December 2012) were gathered by the trained nurses, using an ad hoc developed Resource Use Questionnaire. The following categories of resources were collected: (1) AD-related drugs; (2) other drugs; (3) hospitalizations; (3) visits to the Emergency Department (ED); (4) outpatient visits/exams; (5) social and health interventions provided in the community; (6) care provided by private care workers; (7) hours of informal care provided by the primary and other informal caregivers. In addition, we assessed whether the patient was granted the so-called "indennità di accompagnamento," the care allowance, provided by the Italian Institute for Pensions (INPS) to the people who have ADL and IADL limitations, and need 24-hour assistance. The explicit aim of the "indennità," is to provide the patients with supplementary money, in order to fund the purchase of additional care services.

\section{Cost perspectives and costing activity}

A detailed description of cost categories by perspective is reported in Table 1 . The analysis uses three different cost perspectives, and distinguishes among the costs attributable to the public sector (the National Health Service, the Municipalities, and the State), to private families (i.e. out-of-pocket expenditures) and to society as a whole. Each cost item was assigned to the appropriate perspective, and classified either as "public" or "private." The societal perspective includes both public and private costs and additionally considers the cost of informal care. Cost data were retrieved from official sources when available. In lieu of official sources, the best available data from national and local surveys were used.

Informal caregiving was valuated using a "replacement cost approach" (McDaid, 2001), i.e. estimating the cost of replacing informal caregivers' input with professional assistance. In order to be more conservative in the final estimates (especially as we were not able to distinguish between the hours of supervision and direct care provision, since many families reported 24-hour a day care patterns), we valued the cost of informal caregivers as half of the cost of private care workers, following the approach used by Björkgren et al. (2000) and Poss et al. (2008).

We used a specific assumption to deal with the risk of double-counting the resource consumption when the dyad declared, at the same time, that they received the care allowance and declared out-ofpocket expenditure. As the legal rationale of the "indennità" is to fund out-of-pocket care-related expenditure of families, we subtracted its value from the total out-of-pocket expenditure for all those patients receiving the allowance. When the value of the "indennità" was higher than out-of-pocket expenditure (thus hinting that the family uses part of it for other purposes), we replaced negative values with null quantities.

\section{Statistical analyses}

Analyses of socio-demographic characteristics of the sample, level of patients' disease severity, social/educational status, resource consumption, family relationship between patient and caregiver, and caregiving burden were purely descriptive. Regarding the cost analyses, two different approaches were adopted. First, univariate (nonparametric) analyses were performed to compare annual costs, by perspective and patients' age. In this case, a bootstrap method was used to estimate the confidence intervals of each cost item. Second, a Generalized Linear Model (GLM) was used to study the relation between costs and independent variables (Schwarzkopf et al., 2012; Lindholm et al., 2013). Model validation was carried out using the following tests: $\chi^{2}$ for the family chosen; Pearson correlation, Pregibon link, modified Hosmer, and 
Table 1. Cost categories, by perspective, included in the study

\begin{tabular}{|c|c|c|}
\hline TYPE OF COST & SOURCE & COST PER UNIT \\
\hline \multicolumn{3}{|l|}{ Public cost } \\
\hline Drugs & National Formulary of Drugs (v.2013/06/24) & n.a. \\
\hline Out-patient care & National tariffs list & n.a. \\
\hline Emergency Department & Mean cost retrieved from a national survey & $€ 242 / \mathrm{ED}$ visit \\
\hline Hospitalization & DRG tariff in the Marche Region & n.a. \\
\hline \multicolumn{3}{|l|}{ Community care } \\
\hline GP home visits & GP regional contract & $€ 18.9 /$ visit \\
\hline Home healthcare & Labor cost from national contract - NHS & $€ 24 / \mathrm{h}$ \\
\hline Home help & Labor cost from national contract - cooperatives & $€ 18 / \mathrm{h}$ \\
\hline $\mathrm{AD}$ daycare centers & Mean cost retrieved from a regional survey & $€ 30 / \mathrm{d}$ \\
\hline Care allowance & Value set by national laws & $€ 499.27 / \mathrm{mo}$ \\
\hline \multicolumn{3}{|l|}{ Out-of-pocket expenditure } \\
\hline Drugs not reimbursed & National Formulary of Drugs (v.2013/06/24) & n.a. \\
\hline Out-patient care & National tariffs list & n.a. \\
\hline AD day care center copayment & Regional survey & $€ 30 / \mathrm{d}$ \\
\hline Private care workers & Estimation of care staff cost & $€ 7.5 / \mathrm{h}$ \\
\hline \multicolumn{3}{|l|}{ Informal care } \\
\hline Informal caregivers & Valued as half of the cost of private care workers & $€ 3.75 / \mathrm{h}$ \\
\hline
\end{tabular}

n.a. = not applicable; $\mathrm{AD}=$ Alzheimer's disease $\mathrm{DRG}=$ diagnosis related group $\mathrm{ED}=$ Emergency Department; $\mathrm{GP}=$ general practitioner; NHS $=$ National Health Service.

Lemeshow for link function utilized. These tests suggested not to use the out-of-pocket expenditure as a dependent variable, given its excessively skewed distribution. Therefore, we chose to use the sum of public and private costs as a proxy variable to investigate the patterns of out-of-pocket expenditure in the sample.

\section{Results}

General characteristics of AD patient-caregiver dyads included in the analysis are reported in Table 2. Patients were more frequently women, with a mean age of 81.5 years. Their ADLhierarchy scale score was 1.5 out of 6 , while their IADL performance indicated greater impairment, reaching 35.1 out of 48 on the IADL scale. Caregivers too, were mostly women $(66.2 \%)$, usually children of the patients $(55.7 \%)$ or a spouse/partner (30.8\%). Only $8.2 \%$ of the caregivers had a university or higher degree, $36.7 \%$ completed high school, whereas the majority only finished intermediate school $(24.9 \%)$ or primary school/no title $(30.1 \%)$. The level of caregiving burden, measured using the CBI, reached an average of 27.6 points $( \pm 16.8)$.

Prevalence of service use by $\mathrm{AD}$ patients is reported in Figure 1. As a consequence of the inclusion criteria, all patients relied on family caregiving. Ninety-one percent of the patients used AD-related drugs, composed of antidementia compounds, prescribed by the AEUs, antidepressants, antipsychotics, anxiolytics, and hypnotics/sedatives, and $81 \%$ of them used other drugs. Fifty-five percent of the patients reported outpatient visits and exams in the six months prior to the interview, and $29 \%$ were assisted by a private care worker. Hospitalizations were somewhat frequent in the sample $(7 \%)$, as were visits to the Emergency Department (12\%).

The estimated societal burden of $\mathrm{AD}$ patients was about $€ 20,000 / y r$ (Table 3 ). Out of this, the cost borne by the public sector was $€ 4,534 / \mathrm{yr}$. This value included the cost for direct care services - provided by the NHS and the Municipalities - plus the value of the cash allowances granted by the Italian National Institute of Pensions (INPS). The latter was indeed the largest driver of public cost: $39 \%$ of patients received the grant for a total yearly mean cost of $€ 2,324$. The other significant driver of public expenditure was prescription drugs for $\mathrm{AD}$ and co-morbid diseases, which amounted to $€ 1,402 / \mathrm{yr}$, or almost $1 / 3$ of total public spend. Antidementia drugs were used by approximately $51 \%$ of patients, which accounted for the majority of $\mathrm{AD}$ drug costs (84\%) (see Table S1, available as supplementary material attached to the electronic version of this paper at www.journals.cambridge.org/jid_IPG). The most frequently used drugs for co-morbid diseases were cardiovascular drugs $(40.1 \% ; 31.1 \%$ cost composition), drugs for the alimentary tract and metabolism (19.7\%; 18.2\% cost composition), 
Table 2. Characteristics of the dyads patient/caregiver in the final sample $(n=438)$

\begin{tabular}{|c|c|c|}
\hline & $N$ OR MEAN & $(\%$ OR $\pm \mathrm{SE})$ \\
\hline Patients & 438 & \\
\hline Gender (female) & 272 & $(62.1 \%)$ \\
\hline Age (years) & 81.5 & $( \pm 5.7)$ \\
\hline MMSE & 16 & $( \pm 3.0)$ \\
\hline IADL & 35.1 & $( \pm 13.4)$ \\
\hline $\mathrm{ADL}$ & 1.5 & $( \pm 1.6)$ \\
\hline Behavioral disturbance & 116 & $(26.5 \%)$ \\
\hline Caregivers & 438 & \\
\hline Gender & 290 & $(66.2 \%)$ \\
\hline Age & 61.4 & $( \pm 13.0)$ \\
\hline \multicolumn{3}{|l|}{ Relationship } \\
\hline Spouse/partner & 135 & $(30.8 \%)$ \\
\hline Son/daughter & 244 & $(55.7 \%)$ \\
\hline Other relative & 59 & $(13.5 \%)$ \\
\hline \multicolumn{3}{|l|}{ Educational level } \\
\hline No title/primary school & 132 & $(30.1 \%)$ \\
\hline Intermediate school & 109 & $(24.9 \%)$ \\
\hline High school & 161 & $(36.7 \%)$ \\
\hline University degree or higher & 36 & $(8.2 \%)$ \\
\hline \multicolumn{3}{|l|}{ Social class } \\
\hline Not attributed & 35 & $(8.1 \%)$ \\
\hline Lower & 117 & $(26.8 \%)$ \\
\hline Middle & 79 & $(18.0 \%)$ \\
\hline Middle-upper & 145 & $(33.1 \%)$ \\
\hline Upper & 54 & $(12.3 \%)$ \\
\hline Caregiver burden inventory & 27.6 & $( \pm 16.8)$ \\
\hline \multicolumn{3}{|c|}{ Hours of informal care provided (per week) } \\
\hline Primary caregiver & 50.2 & $( \pm 50.3)$ \\
\hline Other caregivers & 20.2 & $( \pm 31.3)$ \\
\hline
\end{tabular}

$\mathrm{ADL}=$ activities of daily living; $\mathrm{IADL}=$ instrumental activities of daily living; MMSE $=$ Mini-Mental State Examination; SE $=$ standard error of the mean.

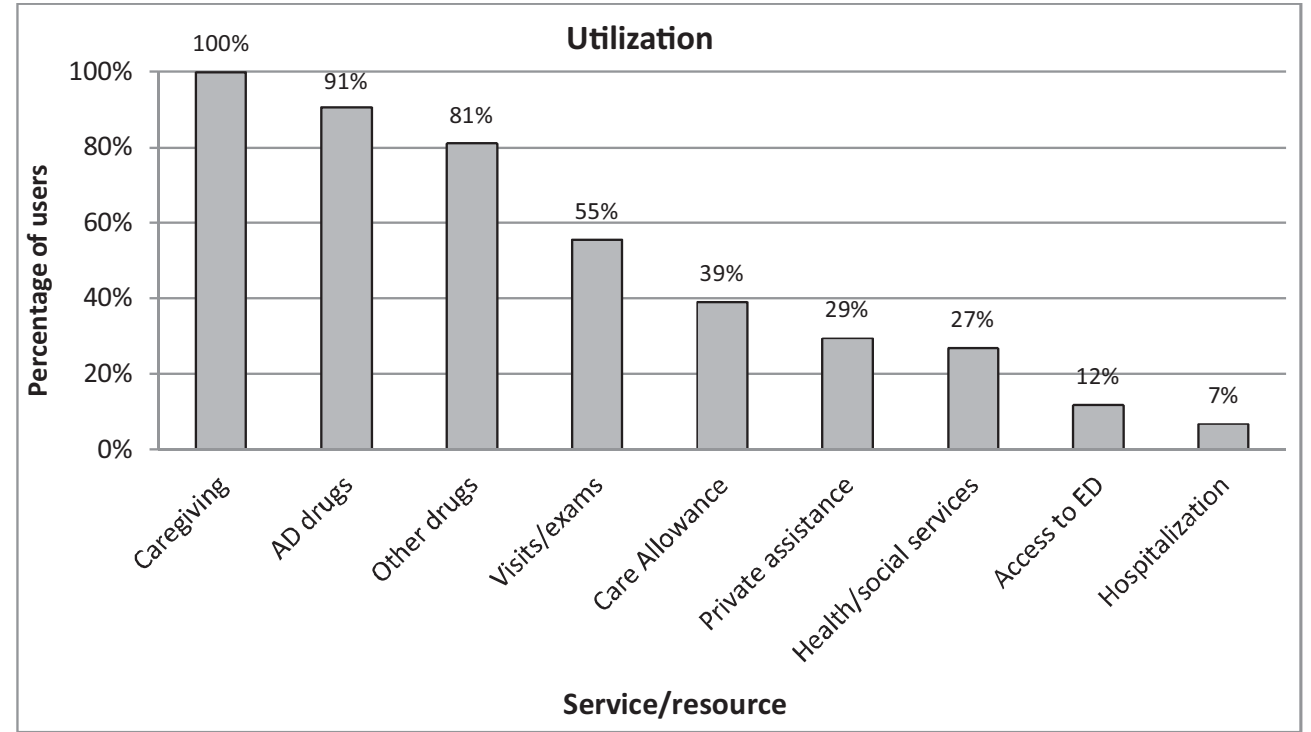

Figure 1. Frequency of resource use $(n=438)$

AD (Alzheimer's Disease), ED (Emergency Department). 
Table 3. AD-related costs, by type of cost and perspective $(n=438)$

\begin{tabular}{|c|c|c|c|c|}
\hline $\begin{array}{l}\text { PERSPECTIVE/TYPE } \\
\text { OF COST }\end{array}$ & $\begin{array}{l}\text { 6-MONTH MEAN } \\
\operatorname{COST}(€)\end{array}$ & {$\left[\begin{array}{lll}95 \% & \mathrm{CI}\end{array}\right]$} & $\begin{array}{l}\text { ESTIMATED } \\
\text { YEARLY COST } \\
(€)\end{array}$ & $\begin{array}{l}\% \text { OF } \\
\text { SOCIETAL } \\
\text { BURDEN }\end{array}$ \\
\hline Public cost & 2,267 & {$[2,041.2-2,492.8]$} & 4,534 & 22.5 \\
\hline Alzheimer's drugs & 446 & [412.7-478.9] & 892 & 4.4 \\
\hline Other drugs & 255 & [160.5-349.4] & 510 & 2.5 \\
\hline Exams/visits & 20 & [15.8-23.8] & 40 & 0.2 \\
\hline $\begin{array}{l}\text { Health and social } \\
\text { interventions }\end{array}$ & 30 & [19.3-39.8] & 60 & 0.3 \\
\hline Emergency & 31 & {$[22.6-40.4]$} & 62 & 0.3 \\
\hline \multicolumn{5}{|l|}{ Department } \\
\hline Hospitalizations & 323 & [167.6-477.9] & 646 & 3.2 \\
\hline State care allowances & 1,162 & {$[1,030.0-1,295.3]$} & 2,324 & 11.5 \\
\hline Patient cost & 1,487 & {$[1,486.6-1,742.3]$} & 2,974 & n.a. \\
\hline Alzheimer's drugs & 12 & {$[7.1-17.1]$} & 24 & n.a. \\
\hline Other drugs & 24 & [12.6-34.5] & 48 & n.a. \\
\hline Exams/visits & 1 & {$[0.4-1.1]$} & 2 & n.a. \\
\hline Health and social & 7 & {$[4.0-9.2]$} & 14 & n.a. \\
\hline interventions & & & & \\
\hline Private assistance & 1,444 & {$[1,185.6-1,701.6]$} & 2,888 & n.a. \\
\hline $\begin{array}{l}\text { Patient cost subtracting } \\
\text { the allowance }{ }^{\mathrm{a}}\end{array}$ & 1,001 & {$[795.7-1,207.2]$} & 2,002 & 14.3 \\
\hline Informal care & 6,795 & {$[6,241.5-7,348.7]$} & 13,590 & 67.5 \\
\hline (Main) caregiver & 4,843 & {$[4,379.8-5,306.2]$} & 9,686 & 48.1 \\
\hline Other caregivers & 1,952 & {$[1,674.4-2,229.9]$} & 3,904 & 19.4 \\
\hline Societal $\cos \mathrm{t}^{\mathrm{b}}$ & 10,064 & {$[9,437.4-10,689.7]$} & 20,128 & 100.0 \\
\hline
\end{tabular}

$\mathrm{AD}=$ Alzheimer's disease $\mathrm{CI}=$ confidence interval $€=$ Euro.

a See the methodological section for details on how the value is computed.

bocietal cost includes: public cost, patient cost without allowance, and informal care cost.

and blood and blood-forming organ medications (17.2\%; 25.3\% cost composition) (see Table S2, available as supplementary material attached to the electronic version of this paper at www.journals.cambridge.org/jid_IPG).

Out-of-pocket expenditure predominantly concerned the cost of hiring private care workers, while the cost for privately purchased drugs was rather limited ( $€ 24$ and $€ 48$ for Alzheimer and other drugs, respectively).

The largest share of societal burden, however, comprised informal care. Even by valuing the hours of care, provided by family caregivers, at half the rate of the lowest skilled labor (private care workers), the value of the societal burden peaked at $€ 13,590 / \mathrm{yr}(67.5 \%$ of total costs). Forty-seven percent of caregivers (primary + secondary) expended $41-168 \mathrm{~h} / \mathrm{wk}$ assisting the patient (see Figure S1, available as supplementary material attached to the electronic version of this paper at www.journals.cambridge.org/jid_IPG). Ten percent of households spent $>168 \mathrm{~h} / \mathrm{wk}$ caring for the $\mathrm{AD}$ patient, while $33 \%$ and $10 \%$ of family members spent, respectively, $15-40$ and $0-14 \mathrm{~h} / \mathrm{wk}$ looking after the Alzheimer's patient. The family members who spent the majority of time on caregiving were spouses/partners $(70 \mathrm{~h} / \mathrm{wk})$ followed by grandchildren $(44 \mathrm{~h} / \mathrm{wk})$ and children-in-law ( $30 \mathrm{~h} / \mathrm{wk}$ ) (see Figure S2, available as supplementary material attached to the electronic version of this paper at www.journals.cambridge.org/jid_IPG).

Predictors of total costs are shown in Table 4. IADL dependency was the only significant predictor of public cost. IADL impairment also influenced the consumption of resources when considering the total public and private expenditure. In addition, the sum of public and private expenditure correlated with higher level of education. Again, impaired IADL status was associated with increased societal cost, whereas cognitive impairment was negatively correlated. Among the characteristics of caregivers, only CBI score was associated with increased societal expenditure.

\section{Discussion}

Our study sheds light on the overall burden of AD in a population of patients at a moderate stage of the disease. By examining the costs using three different perspectives, the expenditure of the public sector (the State, the Municipalities and the NHS) 
Table 4. Predictors of total costs (all perspectives; $n=438$ )

\begin{tabular}{|c|c|c|c|}
\hline MODEL & COEFF. & STANDARD ERROR & $p$ \\
\hline \multicolumn{4}{|l|}{ Model 1. Predictors of public cost } \\
\hline • IADL & 0.0291 & 0.001 & 0.001 \\
\hline \multicolumn{4}{|l|}{ Model 2. Predictors of public + private cost } \\
\hline • IADL & 0.0375 & 0.006 & 0.001 \\
\hline - Educational level: high school versus no title/primary level & 0.6188 & 0.261 & 0.018 \\
\hline \multicolumn{4}{|l|}{ Model 3. Predictors of societal cost } \\
\hline - MMSE & -0.0302 & 0.010 & 0.002 \\
\hline - IADL & 0.0247 & 0.003 & 0.001 \\
\hline • CBI & 0.006 & 0.002 & 0.005 \\
\hline
\end{tabular}

All models are adjusted for characteristics of patients (age, gender, ADL, IADL, and MMSE) and caregivers (age, gender, CBI, statuses, and education level).

$\mathrm{ADL}=$ activities of daily living; $\mathrm{CBI}=$ Caregiver Burden Inventory; IADL = instrumental activities of daily living; MMSE = Mini-Mental State Examination; Coeff. = correlation coefficient; $p=$ probability; Standard Error $=$ standard error of the mean.

was relatively low compared to the overall societal burden. The preference of the Italian Welfare State for cash-for-care allowances, instead of direct care services, was clearly reflected by our results (Shutes and Chiatti, 2012). The cost for care allowances overwhelmed the cost for direct care provision. In many cases the total cost of the care subsidy exceeded that of out-of-pocket expenditure by recipients, suggesting that a substantial part of the allowance was spent in other ways. This reinforces the widespread idea, that in Italy, this care subsidy is a form of compensation for carers' work and complements the income of Italian families. The implications for social policy are indeed relevant and suggest the need for new regulations to increase the accountability of how the care allowance is used.

Prescription drug expenditure accounted for the largest share of the remaining public cost, while the amount of public spending for care services in the community was negligible. Another emerging characteristic was the relevance of the support provided by private care workers (Chiatti et al., 2013a), which represented the major driver of outof-pocket expenditure.

Two previous cost-of-illness studies have been carried out in Italy (Cavallo and Fattore, 1997; Trabucchi, 1999), however, neither study assessed the costs of medical care. This reflected the structure of dementia care in the country, which traditionally falls outside of the NHS. Moreover, neither study included information on disease severity, nor were they based on a large sample of $\mathrm{AD}$ patients assessed by specifically trained research nurses. Cavallo and Fattore's study was based on a postal survey (Cavallo and Fattore, 1997), while the CoDem study (Trabucchi, 1999) included only 103 $\mathrm{AD}$ patients. In these two investigations, the level of informal care ranged from $61.6 \mathrm{~h} / \mathrm{wk}$ (for personal support only) to $124.6 \mathrm{~h} / \mathrm{wk}$ for patients with severe dementia (a Clinical Dementia Rating score of 3). In our study, the number of hours of informal care provided by the primary caregiver (supervision + direct care) peaked to a mean of $50.2 \mathrm{~h} / \mathrm{wk}$, to which must be added an extra $20 \mathrm{~h} / \mathrm{wk}$ from other informal caregivers.

The importance of informal assistance provided by Italian families, outside of the market, was evident in two ways. First, the value of the social cost peaked at $€ 13,590 / \mathrm{yr}$ or $67.5 \%$ of total costs. Second, the public expenditure was significantly less than those same patients would incur in residential care. In the Marche Region, where our study is being carried out, the cost for a year spent in institutional care, for a patient with moderate $\mathrm{AD}$, could vary from $€ 12,045$ to $€ 14,600$, in contrast to $€ 4,534$ for public expenditure of patients living at home, observed in our sample (Marche, 2010). The crucial role of informal caregiving is not limited to Italy. In a recent study carried out in Germany, total costs for community-based caring, after adjusting for age, gender, functional status (ADL and IADL), and co-morbidity, were higher than total costs for nursing home-based caring, mainly due to the higher costs of informal care (Konig et al., 2014). From a State perspective in the short term, the "convenience" of these care arrangements in the community is apparent, since the alternative, residential care settings, is clearly more burdensome. However, if caregivers are not adequately supported, these savings may be soon offset, given the high burden, stress, and often advanced age of caregivers, which expose them to a higher risk of morbidity and mortality (Vitaliano et al., 2003). Already the caregivers in our sample population were close to the threshold for anxiety and depression (McDowell, 2006; Chiatti et al., 2015). Studies have determined that these mood disorders were associated with much higher public 
costs for older people living at home (Vasiliadis et al., 2013), as well as healthcare costs for older patients (Luppa et al., 2008).

In this study, we distinguished the share of cost directly attributable to $\mathrm{AD}$ from that which might be associated with other diseases and/or physical dependency. In this regard, previous evidence pointed out that potentially sizeable savings could be achieved by the management of co-morbidities in people with dementia (Knapp et al., 2013). We found that a large share of the public costs was related to disease co-morbidities (e.g. drugs and hospitalizations), suggesting the need to specifically target this population, for instance, by improving prescription appropriateness through medication reviews and/or improving the compliance to therapy.

In the regression analysis of cost predictors, functional impairment, rather than cognitive impairment, more consistently predicted the use of resources. (The only exception was the correlation between a higher MMSE score and overall societal burden.) This is in line with previous evidence (Lindholm et al., 2013), suggesting that IADL dependency is the main driver of care cost among $\mathrm{AD}$ patients. We found no socioeconomic correlates of public spending, which is consistent with the mission of the Italian welfare system to universally provide assistance (although the overall level dispensed is relatively small). Conversely, the role of caregiver education suggested the probable association between a higher SES and a higher expenditure for the care of the AD patients. These findings raise the issue of equity of care, since it reveals the additional risk of caregiving burden, for those families with lower financial means. The disadvantages of dyads with a lower educational status will increase as the public support for dementia continues to retrench as a result of the financial crisis in the Mediterranean countries.

Caregiver social class was not significantly correlated with $\mathrm{AD}$ burden in the multivariate analysis, once educational attainment was inserted into the models. This suggests that caregiver educational level has a stronger impact in determining the care arrangements of the patients, which may also be connected to the fact that, due to a limitation of the study questionnaire, we could not measure family social class, but only individuals' social class (Erikson, 1984)

The study has other limitations, which must be considered when appraising its results. First of all, regarding the representativeness of the sample, it has to be mentioned, that at the present time, no data are available regarding the prevalence of $\mathrm{AD}$ in the Marche Region and the characteristics of the population of caregivers. This is a major issue for the Regional Government, which the UP-TECH project is actually trying to address. However, the $67 \%$ recruitment response rate achieved on the lists of the AEU patients (which include all patients of the Region with a diagnosis of $\mathrm{AD}$ ) and the large size of the sample ( $n=438$ patient-caregiver dyads), make us optimistic regarding the latter's representativeness of Marche's population of patients with moderate $\mathrm{AD}$, living in the community, with at least one family caregiver. The characteristics of the UPTECH sample are indeed consistent with those of the samples enrolled by other studies (both RCTs and cross-sectional studies) targeting patients with dementia (Coon et al., 2003; Sink et al., 2006; Black et al., 2013) and those with moderate AD (Wisniewski et al., 2003; Belle et al., 2006). In these studies, the caregivers had a very similar age and gender composition, while the dementia patients had a comparable profile in terms of age, gender, MMSE score, and ADL and IADL dependency. A second potential limitation of the paper refers to the inclusion criteria of our study population, i.e., patients with moderate $\mathrm{AD}$, with at least one family caregiver. This implies that those patients without a family caregiver - although their number should be relatively small in the Italian population were not included in the analysis. A third limitation relates to the lack of conventional measures of $\mathrm{AD}$ symptom gravity, such as the NPI (Cummings, 1997) and the Behave-AD (Reisberg et al., 1996), in the UP-TECH study. However, we tried to address this by using the caregivers' reports of behavioral disturbances, which is a very common proxy in the health economic analysis of $\mathrm{AD}$ cost (Jonsson and Wimo, 2009). Last but not least, for some cost items, we could not use the actual price, but had to rely on an estimate from either surveys or the cost of labor set by the national employment contracts. Even with these limitations, our up-to-date study is one of the most realistic carried out in Italy, as it is based on a comprehensive and reliable collection of data, following an intensive training of nurse assessors and a continuous monitoring of a large number of patients.

\section{Conflict of interest}

None.

\section{Description of authors' roles}

CC contributed to the statistical analysis and interpretation; the conception, development and writing of the paper. GF contributed to the 
statistical analysis and interpretation; the development and writing of the paper. JMR contributed to the conception, development, and writing of the paper. FD contributed to the statistical analysis and interpretation; the development and writing of the paper. FB contributed to the execution of the study; data preparation; critical comments on paper drafts. LC provided critical comments on paper drafts; critical review of paper drafts. FM contributed to the execution of the study; management of participant recruitment; supervision of data collection; data preparation; critical review of paper drafts. AC provided critical comments on paper drafts; critical review of paper drafts. FL supervised the data collection and provided critical comments on paper drafts.

\section{Acknowledgments}

This work was supported by the Marche Region under the Special Fund for Dependency Care managed by the Italian Ministry of Welfare (" $I l$ progetto UPTECH è realizzato dalla Regione Marche in collaborazione e con il contributo dell'INRCA Ancona attraverso il finanziamento del Fondo Nazionale non Autosufficienza, 2010”).

\section{Supplementary Material}

To view supplementary material for this article, please visit http://dx.doi.10.1017/ S104161021500040X

\section{References}

Albert, M. S. et al. (2011). The diagnosis of mild cognitive impairment due to Alzheimer's disease: Recommendations from the national institute on aging-Alzheimer's association workgroups on diagnostic guidelines for Alzheimer's disease. Alzheimer's and Dementia, 7, 270-279.

Barberger-Gateau, P., Commenges, D., Gagnon, M., Letenneur, L., Sauvel, C. and Dartigues, J. F. (1992). Instrumental activities of daily living as a screening tool for cognitive impairment and dementia in elderly community dwellers. Fournal of the American Geriatrics Society, 40, 1129-1134.

Belle, S. H. et al. (2006). Enhancing the quality of life of dementia caregivers from different ethnic or racial groups: a randomized, controlled trial. Annals of Internal Medicine, 145, 727-738.

Björkgren, M. A., Fries, B. E. and Shugarman, L. R. (2000). A Rug-III case-mix system for home care. Canadian fournal on Aging, 19, 106-125.

Black, B. S., Johnston, D., Rabins, P. V., Morrison, A., Lyketsos, C. and Samus, Q. M. (2013). Unmet needs of community-residing persons with dementia and their informal caregivers: findings from the maximizing independence at home study. Fournal of the American Geriatrics Society, 61, 2087-2095.

Boada, M. et al. (1999). Costs of health care resources of ambulatory-care patients diagnosed with Alzheimer's disease in Spain. Medicina Clinica, 113, 690 695.

Cardano, M., Costa, G. and Demaria, M. (2004). Social mobility and health in the turin longitudinal study. Social Science $\mathcal{E}$ Medicine, 58, 1563-1574.

Cavallo, M. C. and Fattore, G. (1997). The economic and social burden of Alzheimer disease on families in the Lombardy region of Italy. Alzheimer Disease $\mathcal{E}$ Associated Disorders, 11, 184-190.

Chiatti, C., Di Rosa, M., Melchiorre, M. G., Manzoli, L., Rimland, J. M. and Lamura, G. (2013a). Migrant care workers as protective factor against caregiver burden: results from a longitudinal analysis of the EUROFAMCARE study in Italy. Aging \& Mental Health, 17, 609-614.

Chiatti, C. et al. (2013b). The UP-TECH project, an intervention to support caregivers of Alzheimer's disease patients in Italy: study protocol for a randomized controlled trial. Trials, 14, 155.

Chiatti, C. et al. (2015). The UP-TECH project, an intervention to support caregivers of Alzheimer's disease patients in Italy: preliminary findings on recruitment and caregiving burden in the baseline population. Aging $\mathcal{E}$ Mental Health, 19, 517-525.

Coon, D. W., Thompson, L., Steffen, A., Sorocco, K. and Gallagher-Thompson, D. (2003). Anger and depression management: psychoeducational skill training interventions for women caregivers of a relative with dementia. The Gerontologist, 43, 678-689.

Costa, N. et al. (2012). Methodological considerations in cost of illness studies on Alzheimer disease. Health Economics Review, 2, 18.

Cummings, J. L. (1997). The Neuropsychiatric Inventory: assessing psychopathology in dementia patients. Neurology, 48, S10-S16.

De Lillo, A. and Schizzerotto, A. (1985). La Valutazione Sociale delle Occupazioni. Una Scala di Stratificazione Occupazionale per l'Italia Contemporanea. Bologna, Italia: Il Mulino.

Erikson, R. (1984). Social class of men, women and families. Sociology, 18, 500-514.

Ferri, C. P. et al. (2005). Global prevalence of dementia: a Delphi consensus study. Lancet, 366, 2112-2117.

Folstein, M., Folstein, S. and Mchugh, P. (1975). 'Mini-mental state'. A practical method for grading the cognitive state of patients for the clinician. Fournal of Psychiatric Research, 12, 189-198.

Hirdes, J. et al. (2010). interRAI Contact Assessment (CA) Form and User's Manual, 9.2. Ann Arbor, MI: InterRAI.

Huisman, M., Kunst, A. E. and Mackenbach, J. P. (2003). Socioeconomic inequalities in morbidity among the elderly: a European overview. Social Science and Medicine, 57, 861-873.

Hurd, M. D., Martorell, P., Delavande, A., Mullen, K. J. and Langa, K. M. (2013). Monetary costs of dementia in the United States. The New England Fournal of Medicine, 368, 1326-1334. 
Hux, M. J., O'Brien, B. J., Iskedjian, M., Goeree, R., Gagnon, M. and Gauthier, S. (1998). Relation between severity of Alzheimer's disease and costs of caring. Canadian Medical Association fournal, 159, 457-465.

Jonsson, L. and Wimo, A. (2009). The cost of dementia in Europe: a review of the evidence, and methodological considerations. Pharmacoeconomics, 27, 391-403.

Jorm, A. F. and Jolley, D. (1998). The incidence of dementia: a meta-analysis. Neurology, 51, 728-733.

Knapp, M., Iemmi, V. and Romeo, R. (2013). Dementia care costs and outcomes: a systematic review. International Fournal of Geriatric Psychiatry, 28, 551-561.

Konig, H. H. et al. (2014). The costs of dementia from the societal perspective: is care provided in the community really cheaper than nursing home care? Fournal of the American Medical Directors Association, 15, 117-126.

Leicht, H. et al. (2013). Predictors of costs in dementia in a longitudinal perspective. PLoS One, 8, e70018.

Leon, J., Cheng, C. K. and Neumann, P. J. (1998). Alzheimer's disease care: costs and potential savings. Health Affairs, 17, 206-216.

Lindholm, C., Gustavsson, A., Jonsson, L. and Wimo, A. (2013). Costs explained by function rather than diagnosis-results from the SNAC Nordanstig elderly cohort in Sweden. International fournal of Geriatric Psychiatry, 28, 454-462.

Luppa, M., Heinrich, S., Angermeyer, M. C., Konig, H. H. and Riedel-Heller, S. G. (2008). Healthcare costs associated with recognized and unrecognized depression in old age. International Psychogeriatrics, 20, 1219-1229.

Marche (2010). DGR 1729 "Model convention of sheltered housing for older people" Marche Region Italy.

Marvardi, M. et al. (2005). The caregiver burden inventory in evaluating the burden of caregivers of elderly demented patients: results from a multicenter study. Aging Clinical and Experimental Research, 17, 46-53.

Mcdaid, D. (2001). Estimating the costs of informal care for people with Alzheimer's disease: methodological and practical challenges. International fournal of Geriatric Psychiatry, 16, 400-405.

Mcdowell, I. (2006). Measuring Health: A Guide to Rating Scales and Questionnaires, 3rd edn. Oxford, New York: Oxford University Press.

Mckhann, G. M. et al. (2011). The diagnosis of dementia due to Alzheimer's disease: recommendations from the national institute on aging-Alzheimer's association workgroups on diagnostic guidelines for Alzheimer's disease. Alzheimer's E Dementia, 7, 263-269.

Morris, J. N., Fries, B. E. and Morris, S. A. (1999). Scaling ADLs within the MDS. The fournals of Gerontology, Series A: Biological Sciences $\mathcal{E}$ Medical Sciences, 54, M546-M553.
Novak, M. and Guest, C. (1989). Application of a multidimensional caregiver burden inventory. The Gerontologist, 29, 798-803.

Poss, J. W., Hirdes, J. P., Fries, B. E., Mckillop, I. and Chase, M. (2008). Validation of resource utilization groups version III for home care (RUG-III/HC): evidence from a Canadian home care jurisdiction. Medical Care, 46, 380-387.

Prince, M. (2004). Care arrangements for people with dementia in developing countries. International fournal of Geriatric Psychiatry, 19, 170-177.

Reisberg, B., Auer, S. R. and Monteiro, I. M. (1996). Behavioral pathology in Alzheimer's disease (BEHAVE-AD) rating scale. International Psychogeriatrics, 8 (Suppl. 3), 301-308.

Schneider, J., Murray, J., Banerjee, S. and Mann, A. (1999). EUROCARE: a cross-national study of co-resident spouse carers for people with Alzheimer's disease: i-factors associated with carer burden. International fournal of Geriatric Psychiatry, 14, 651-661.

Schwarzkopf, L. et al. (2012). Excess costs of dementia disorders and the role of age and gender - an analysis of German health and long-term care insurance claims data. BMC Health Services Research, 12, 165.

Shutes, I. and Chiatti, C. (2012). Migrant workers and emerging care markets in italy and UK. Fournal of European Social Policy, 22, 392-405.

Sink, K. M., Covinsky, K. E., Barnes, D. E., Newcomer, R. J. and Yaffe, K. (2006). Caregiver characteristics are associated with neuropsychiatric symptoms of dementia. Fournal of the American Geriatrics Society, 54, 796803.

Thies, W. and Bleiler, L. (2011). Alzheimer's disease facts and figures. Alzheimer's \& Dementia, 7, 208-244.

Trabucchi, M. (1999). An economic perspective on Alzheimer's disease. Fournal of Geriatric Psychiatry and Neurology, 12, 29-38.

Vasiliadis, H. M., Dionne, P. A., Preville, M., Gentil, L., Berbiche, D. and Latimer, E. (2013). The excess healthcare costs associated with depression and anxiety in elderly living in the community. The American fournal of Geriatric Psychiatry, 21, 536-548.

Vitaliano, P., Zhang, J. and Scanlan, J. (2003). Is caregiving hazardous to one's physical health? A meta-analysis. Psychological Bulletin, 129, 946972.

WHO and ADI (2012). Dementia a Public Health Priority. Geneva: World Health Organization.

Wisniewski, S. R. et al. (2003). The resources for enhancing Alzheimer's caregiver health (reach): project design and baseline characteristics. Psychology and Aging, 18, 375384. 